\title{
Effect of curcumin on irradiated and estrogen- transformed human breast cell lines
}

\author{
GLORIA M. CALAF ${ }^{1,2}$, CARLOS ECHIBURÚ-CHAU $^{1}$, GENGYUN WEN $^{2}$, \\ ADAYABALAM S. BALAJEE ${ }^{2}$ and DEBASISH ROY ${ }^{3}$ \\ ${ }^{1}$ Instituto de Alta Investigación, Universidad de Tarapacá, Arica, Chile; ${ }^{2}$ Center for \\ Radiological Research, Columbia University Medical Center, New York, NY, USA; ${ }^{3}$ Department of \\ Natural Science, Hostos College of the City University of New York, New York, NY, USA
}

Received February 15, 2011; Accepted August 5, 2011

DOI: $10.3892 /$ ijo.2011.1228

\begin{abstract}
Curcumin (diferuloyl methane) is a well known antioxidant that exerts antiproliferative and apoptotic effects. Curcumin effect was evaluated in a breast cancer model that was developed using the immortalized breast epithelial cell line MCF-10F after exposure to low doses of high LET (linear energy transfer) $\alpha$ particles $(150 \mathrm{keV} / \mu \mathrm{m})$ of radiation, and subsequently cultured in the presence of $17 \beta$-estradiol (estrogen). This model consisted of human breast epithelial cells in different stages of transformation: i) MCF-10F; ii) Estrogen cell line; iii) a malignant Alpha3 cell line; iv) a malignant and tumorigenic, Alpha5 cell line; and v) a cell line derived from Alpha5 injected into the nude mice that gave rise to Tumor2 cell line. Curcumin decreased anchorage-independent growh in transformed breast cancer cell lines in comparison to their counterparts and increased the percentage of cells from $G_{0} / G_{1}$ with a concomitant increase in $\mathrm{G}_{2} / \mathrm{M}$ phases, as well as a decrease in PCNA and Rho-A protein expression. Among the oncogenes, c-Ha-Ras and Ras homologous A (Rho-A) are important cell signaling factors for malignant transformation and to reach their active GTP bound state, Ras proteins must first release bound GDP mediated by a guanine nucleotide releasing factor (GRF). Then curcumin decrease RasGRF1 protein expression in malignant cell lines. Further, differential expression levels of cleaved (ADP) ribose polymerase 1 (PARP-1) and phosphorylated histone $\mathrm{H} 2 \mathrm{AX}(\gamma-\mathrm{H} 2 \mathrm{AX})$ were observed after curcumin treatment. It seems that PARP-1 similar to $\mathrm{H} 2 \mathrm{AX}$, confers cellular protection against radiation and estrogen-induced DNA damage mediated by curcumin. Therefore, targeting either PARP-1 or $\mathrm{H} 2 \mathrm{AX}$ may provide an effective way of maximizing the therapeutic value of antioxidants for cancer prevention.
\end{abstract}

Correspondence to: Dr Gloria M. Calaf, Instituto de Alta Investigación, Universidad de Tarapacá, Calle Antofagasta no. 1520, Arica, Chile

E-mail: gmc24@columbia.edu

Key words: curcumin, $c$-Ha-Ras, breast cells, radiation, estrogen

\section{Introduction}

Among the antioxidants, curcumin (diferuloyl methane), is a well-known major dietary natural yellow pigment derived from the rhizomes of turmeric the herb knowns as Curcuma longa originary from India and South Asia. It possesses antiproliferative, anticarcinogenic and chemopreventive potential $(1,2)$. The antitumor efficacy of curcumin has been documented in animal models as well as in phase I clinical trials with multiple cancer types (3-7). The molecular targets and therapeutics of curcumin in health and disease have been studied before (5-7). These studies have reported that curcumin had biological and medicinal properties as well as anticancer potential in preclinical and clinical studies. Numerous studies in animals have demonstrated that curcumin has potent chemopreventive activity against a wide variety of tumors. Curcumin has great potential in the prevention and treatment of cancer.

Curcumin has been shown to be chemopreventive and chemotherapeutic by blocking tumor initiation (8-13) induced by benzo[a]pyrene and 7,12 dimethylbenz[a]anthracene; it suppressed phorphol ester-induced tumor promotion; suppressed carcinogenesis of the skin, forestomach; and colon in mice. It has been shown to prevent cancer in colon, skin stomach, duodenum following oral administration (7-9).

Curcumin inhibited cell proliferation, invasion, angiogenesis and metastasis of different cancers through interaction with multiple cell signaling proteins (1). Various molecular targets modulated by this agent include transcription factors, growth factors and their receptors, cytokines, enzymes, and genes regulating cell proliferation and apoptosis (14-17). Curcumin inhibits activation of transcriptional factors such as (AP)-1, nuclear factor-kappa $\mathrm{B}(\mathrm{NF}-\mathrm{\kappa} \mathrm{B})$ and many others that are up-regulated in most cancers. In normal primary human cells, curcumin either stimulates or inhibits proliferation, but does not appear to induce apoptosis. Curcumin reversibly arrests normal mammary epitelial cells at $G_{0} / G_{1}$ phases. However, apoptosis by curcumin was reported in mammary epithelial carcinoma cells at the $\mathrm{G}_{2}$ phase of cell cycle (14-19).

Among the oncogenes, $c$-Ha-Ras and Ras homologous $A$ (Rho-A) from the Ras super family have been shown to promote both cell proliferation and invasion indicating their importance in malignant transformation (20-31). A critical step in the 
stimulation of cell surface receptors by their ligand involves the accumulation of Ras proteins in their active GTP-bound state. To reach their active GTP bound state, Ras proteins must first release bound GDP mediated by a guanine nucleotide releasing factor (GRF). Members of Rho family proteins sometimes act downstream of Ras. The Rho GTPases have been identified as regulators of cytoskeletal reorganization in addition to their effects on cell growth and it has been shown that they are overexpressed in human tumors (20-22).

The DNA damage response is a complex process involving multiple DNA repair, cell survival, and cell death pathways with damage specificity to different types of DNA damage (34-37). The DNA damage includes double-strand breaks (DSB), single strand breaks, base damage, bulky adducts, intra/interstrand cross links, and breakdown of replication fork lesions where one of the key proteins in the base excision repair pathway is the Poly adenosine diphosphate ribose polymerase-1 (PARP-1) $(6,19,32-34)$. PARP-1 is a $116-\mathrm{kDa}$ nuclear protein that appears to be involved in DNA repair predominantly in response to environmental stress $(32,33)$. It is important for cells to maintain their viability and cleavage of PARP facilitates cellular disassembly and serves as a marker of cells undergoing apoptosis.

Accumulation of phosphorylated histone $\mathrm{H} 2 \mathrm{AX}$, also called $\gamma-\mathrm{H} 2 \mathrm{AX}$, is a marker for DSB (35-37). The H2AX, member of the family $\mathrm{H} 2 \mathrm{~A}$, is a subunit of the nucleosome. The phosphorylation of this protein at the serine 139 in the C-tail serine-glutamine-glutamate motif is one of the earliest responses of mammalian cells to ionizing radiation-induced DNA double-stand breaks (DSB) (35-37). H2AX forms discrete foci at the sites of DSBs, facilitates the remodeling complexes to the sites of DNA damage, and influences both the efficiency and fidelity of DSB repair.

To gain insights into the effects of curcumin on breast carcinogenesis an established in vitro experimental breast cancer model (Alpha model) (38-40) induced by radiation and estrogen was used. The aim of this work was to evaluate the effect of curcumin in human breast epithelial cells transformed by the effect of radiation in the presence of estrogen and to identify the biological processes that are altered during the malignant transformation of normal breast epithelial cells.

\section{Materials and methods}

Experimental breast cancer model. The spontaneously immortalized breast epithelial cell line, MCF-10F (ATCC, Manassas, VA) retains all the characteristics of normal epithelium in vitro, including anchorage-dependence, non-invasiveness and nontumorigenicity in nude mice. This cell line was exposed to low doses of high LET (linear energy transfer) alpha particles (150 $\mathrm{keV} / \mu \mathrm{m})$ in the presence of estrogen (17 $\beta$-estradiol) (38). This model consisted of human breast epithelial cells in different stages of transformation: i) normal cells, MCF-10F; ii) MCF-10F cell line treated with estrogen $\left(10^{-8} \mathrm{M}\right)$, called Estrogen cell line; iii) a malignant non-tumorigenic, Alpha3 cell line; iv) a malignant and tumorigenic, Alpha5 cell line; and v) a malignant and tumorigenic cell line derived from Alpha5 injected into the nude mice giving rise to a tumor from which a cell line named Tumor2 was originated. The cell lines were cultured with Dulbecco's modified Eagle's media (DMEM)/F-12 (1:1) supplemented with $100 \mathrm{U} / \mathrm{ml}$ penicillin, $100 \mathrm{mg} / \mathrm{ml}$ strepto- mycin, $2.5 \mathrm{mg} / \mathrm{ml}$ amphotericin B (all from Life Technologies, Grand Island, NY), $10 \mathrm{mg} / \mathrm{ml}$ insulin (Sigma-Aldrich, St. Louis, $\mathrm{MO}$ ), $5 \%$ equine serum (Biofluids, Rockville, MD), $0.5 \mathrm{mg} /$ $\mathrm{ml}$ hydrocortisone (Sigma) and $0.02 \mathrm{mg} / \mathrm{ml}$ epidermal growth factor (Collaborative Research, Bedford, MA). The cells were incubated at $37^{\circ} \mathrm{C}$ with $5 \% \mathrm{CO}_{2}$ up to $70 \%$ confluence.

Growth rate of cells. The growth rate was determined by the doubling time of the cells seeded onto a flask T25 (1x10 5 cells per flask at initial time). To determine the population doubling time cells were counted 24,48 , and $72 \mathrm{~h}$ after plating that was calculated from the exponential portion of the growth curve. Dose-response curve of curcumin was analyzed at doses from 10 to $60 \mu \mathrm{M}$ after 48 -h treatments.

Anchorage-independent assay. To test for cell growth in semisolid medium, curcumin-treated cells were trypsinized and plated at a density of $1 \times 10^{5}$ cells in $10 \mathrm{ml}$ of $0.35 \%$ agarose over a $0.7 \%$ agar base in $100-\mathrm{mm}$ culture dishes as described $(23,24)$. Media were replenished every day and colonies were scored after 21 days in culture.

Cell cycle analysis. The cells were trypsinized then fixed in $70 \%$ ethanol and washed with cold PBS. To assess the DNA content the cells were incubated for $30 \mathrm{~min}$ with propidium iodide staining that was used for measuring by fluorescence-activated cell sorting (FACS propidium iodide/RNase staining buffer) (BD Pharmingen $^{\mathrm{TM}}$ ), covered with aluminium foil and measured using flow cytometry. Percentage of cells in each phase of the cell cycle was analyzed using BD CellQuest Pro software (BectonDickinson, Co.) with an ultraviolet excitation laser beam.

Western blot analysis. Cells were lysated with $1 \mathrm{ml}$ lysis buffer (pH 7.2) [Tris-Base (50 mM), EDTA (1 mM), NaCl (100 mM), PMSF (1 mM), Orthovanadate $(1 \mathrm{mM})$, Triton X-100 $(0.1 \%)]$ and centrifuged (10000 rpm x $10 \mathrm{~min})$. Cellular proteins from the supernatant were dissolved in SDS-PAGE sample solution [60 mM Tris, pH 6.5, 10\% (w/v) glycerol, 5\% (w/v) B-mercaptoethanol, 20\% (w/v) SDS, and $0.025 \%$ (w/v) bromophenol blue] and denatured by boiling $\left(100^{\circ} \mathrm{C} \times 5 \mathrm{~min}\right)$. The total amount of protein used was $20 \mu \mathrm{g}$ per lane with standard protein markers (Bio-Rad Laboratories, Hercules, CA). After fractionation by SDS-PAGE on gels $(7 \times 14 \mathrm{~cm})$, proteins were electroblotted onto nitrocellulose membrane (Amersham, Biosciences, UK) using a blotting apparatus (Bio-Rad Laboratories, Hercules, CA). Prestained SDS-PAGE (Standards) blots were blocked for $2 \mathrm{~h}$ in $10 \%$ defatted dry milk-TBS-0.1\% Tween and then incubated for $2 \mathrm{~h}$ at room temperature with corresponding primary antibodies. The following antibodies were used: PCNA (PC11, sc53407); Ras-GRF1(C18, sc863); RhoA (26C4, sc418) (all from Santa Cruz Biotechnology, CA), cleaved PARP (46D11, rabbit mAb) and phospho-H2AX (Ser 139, 20E3) (both from Cell Signaling, CA) (1: 200) followed by incubation with secondary peroxidaseconjugated monkey, mouse or anti-rabbit IgG (1:5000) (Cell Signaling, CA) in 5\% defatted dry milk-TBS-0.1\% Tween. All steps were performed at room temperature, and blots were rinsed between incubation steps with TBS-0.1\% Tween. Cell blots were probed with mouse anti-actin antibody as control. Immunoreactive bands were visualized by using the ECL ${ }^{\mathrm{TM}}$ detection reagent (Amersham, Dübendorf, Switzerland) and 


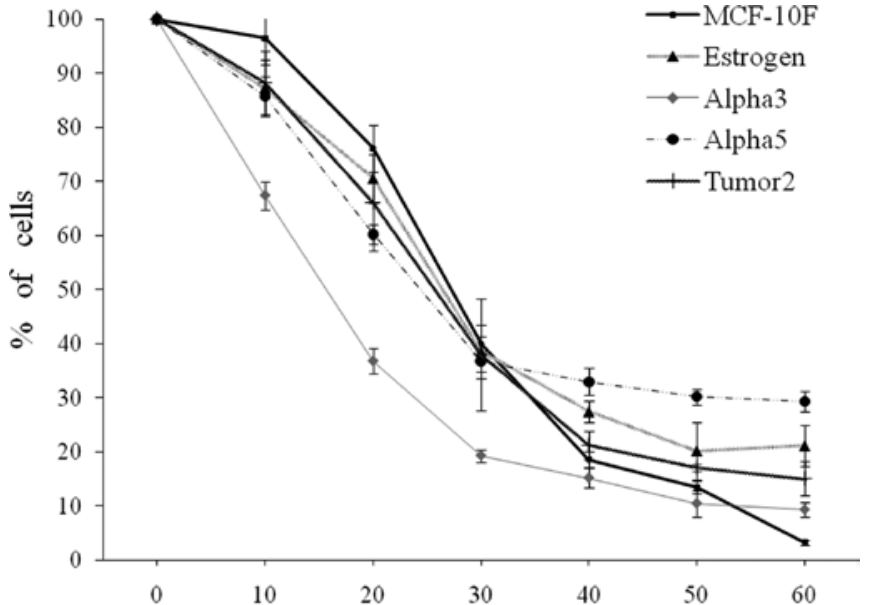

Curcumin dose $(\mu \mathrm{M})$

Figure 1. Effect of curcumin (dose-response curve of 0-60 $\mu \mathrm{M}$ ) on the percentage of MCF-10F, Estrogen, Alpha3, Alpha5 and Tumor 2 cell lines after 2-day treatment. It was determined by using the Coulter Counter apparatus.

exposure of the membrane to X-ray film. Protein levels were determined with the Bicinchoninic acid method (Bio-Rad) and bovine serum albumin to perform the standard curve.

\section{Results}

Dose response curve of curcumin. To determine the dose to be used in all the experiments $0-60 \mu \mathrm{M}$ of curcumin was used for $48 \mathrm{~h}$ of treatment with the five cell lines. Results in Fig. 1 show that the mean $\mathrm{LD}_{50}$ was at $25 \mu \mathrm{M}$ with the exception of Alpha3 cell line which showed an $\mathrm{LD}_{50}$ value of $15 \mu \mathrm{M}$. Then, all the experiments were carried out with either 15 or $30 \mu \mathrm{M}$ curcumin.

Anchorage-independent growth. Previous results with these five cell lines indicated that Alpha3, Alpha5 and Tumor2 were able to form colonies in soft agar. Curcumin at $30 \mu \mathrm{M}$ concentration decreased the colony formation under similar conditions in Alpha3, Alpha5 and Tumor2 cell lines (Fig. 2A). In contrast, there was no colony formation in the control and Estrogen cell lines with or without curcumin treatment.

Effect of curcumin on the cell cycle. Effect of curcumin on cell cycle profiles of the five cell lines with $(30 \mu \mathrm{M})$ and without curcumin treatment was studied (Fig. 2B and Table I) Results indicated that $\mathrm{G}_{1}, \mathrm{~S}$ and $\mathrm{G}_{2} / \mathrm{M}$ phases were altered by curcumin by reducing the percentage of cells in $\mathrm{G}_{0} / \mathrm{G}_{1}$ phase and by increasing the proportion of $\mathrm{G}_{2} / \mathrm{M}$ phase cells. The effect was more pronounced in Alpha3 and Alpha5 than in Tumor 2 cell line.

Effect of curcumin on cell proliferation. We next investigated the level of the major DNA replicating factor, proliferating cell nuclear antigen (PCNA). Immunoperoxidase staining revealed that this cell cycle modulator was reduced with $15 \mu \mathrm{M}$ curcumin in the malignant cell lines Alpha3, Alpha5 and Tumor2. In contrast, MCF-10F and Estrogen cell lines did not show any change (Fig. 3A).
Table I. Effect of curcumin on cell cycle of breast cancer epithelial cell lines.

\begin{tabular}{lccc}
\hline Cell lines & $\mathrm{G}_{0} / \mathrm{G}_{1}(\%)^{\mathrm{a}}$ & $\mathrm{S}(\%)^{\mathrm{a}}$ & $\mathrm{G}_{2} / \mathrm{M}(\%)^{\mathrm{a}}$ \\
\hline MCF-10F & 31.85 & 11.48 & 22.88 \\
MCF-10F + Cur & 33.39 & 16.63 & 19.76 \\
Estrogen & 15.66 & 6.42 & 21.88 \\
Estrogen + Cur & 17.92 & 10.14 & 18.47 \\
& & & \\
Alpha3 & 42.44 & 8.04 & 19.15 \\
Alpha3 + Cur & 33.90 & 12.81 & 29.12 \\
& & & \\
Alpha5 & 52.96 & 7.22 & 22.02 \\
Alpha5 + Cur & 30.5 & 14.57 & 30.77 \\
Tumor2 & & & \\
Tumor2 + Cur & 20.42 & 7.88 & 26.51 \\
\hline
\end{tabular}

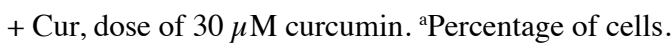

Effect of curcumin on Ras activated state. To analyze the Ras active GTP bound state, the RasGRF1 protein expression was assessed. Expression and quantification of effect of $15 \mu \mathrm{M}$ curcumin in all the cell lines are shown in Figs. 3B and 4. Results indicated that curcumin decreased RasGRF1 protein expression in the control MCF-10F, Apha5 and Tumor2 cell lines by fluorescence staining intensities (Fig. 3B). RasGRF1 protein expression increased in control and Estrogen cell line by the effect of curcumin but decreased in Alpha3, Apha5 and Tumor2 cell lines in the presence of curcumin (Fig. 4).

Effect of curcumin on regulation of actin cytoskeleton. RhoA is a small GTPase protein known to regulate the actin cytoskeleton in the formation of stress fibers and it is generally distributed in the nuclei of cancer cells. Rho-A protein expression was decreased by the effect of $15 \mu \mathrm{M}$ curcumin in normal and malignant cell lines (Fig. 5). This effect was more pronounced in malignant and tumorigenic Alpha5 and Tumor 2 cell lines. The protein expression of Rho-A in malignant Alpha3 cell line was downregulated in comparison to the control cell line.

Effect of curcumin on DNA damage signaling: PARP-1 determination. DNA damage response is a complex process involving multiple DNA repair cell cycle proteins. To determine the effect of curcumin on DNA damage response PARP-1, an important single strand break binding protein, was analyzed (Fig. 6A). PARP-1 protein is cleaved in response to DNA damage in cells undergoing apoptosis and shows that $30 \mu \mathrm{M}$ of curcumin stimulated cleaved PARP-1 protein expression in control MCF-10F, estrogen, Alpha3 and Tumor2. In the case of Alpha5 cell line there was a decrease in cleavage by curcumin treatment. Collectively, these results suggest that curcumin induces apoptosis in breast cancer cells. 


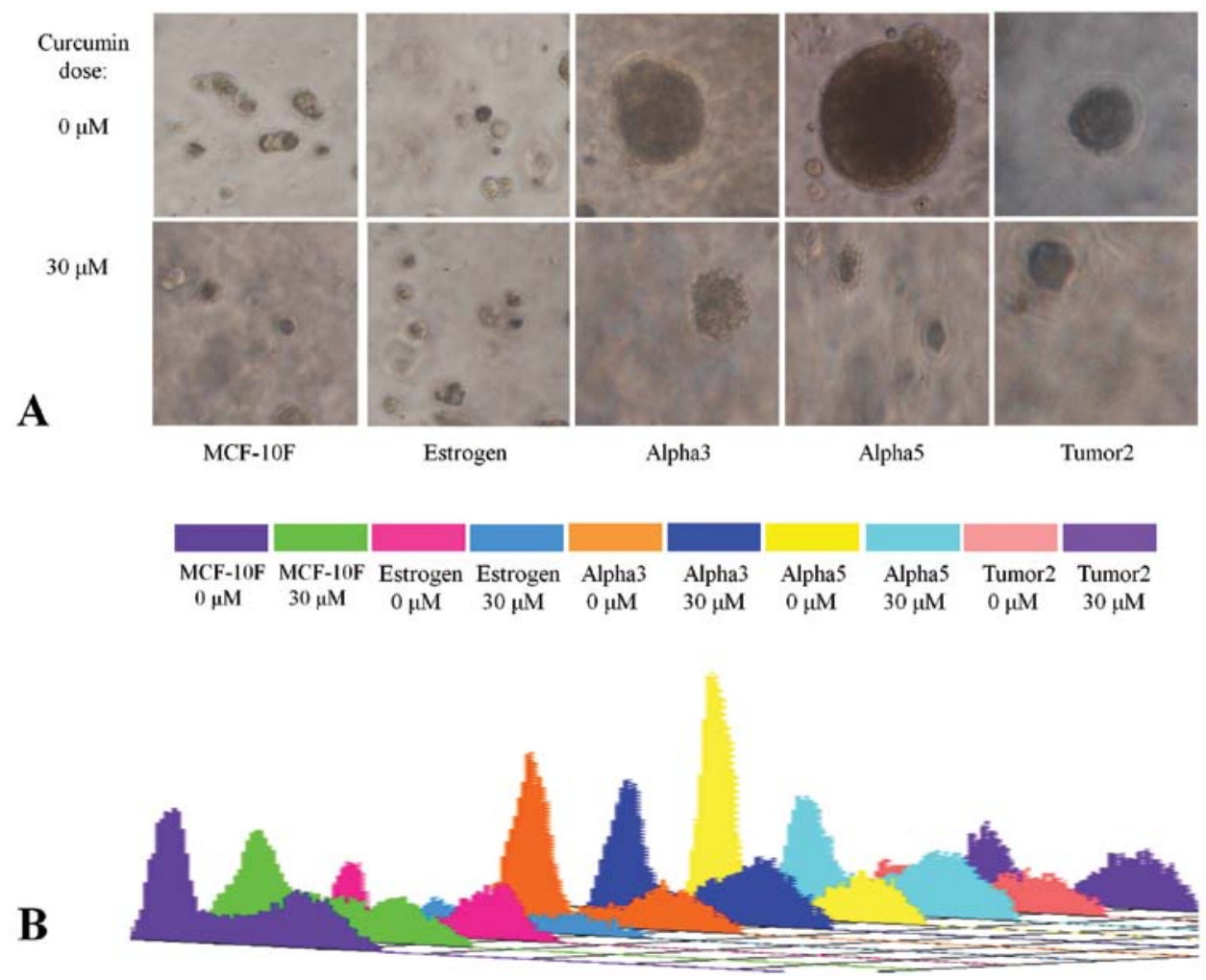

Figure 2. (A) Effect of curcumin treatment $(0$ and $30 \mu \mathrm{M})$ on anchorage-independent growth assay in MCF-10F, Estrogen, Alpha3, Alpha5 and Tumor2 cell lines. Soft agar method was used. Colonies were analyzed after 21 days. (B) Effect of curcumin treatment $(0$ and $30 \mu \mathrm{M})$ on cell cycle analyses in MCF-10F, Estrogen, Alpha 3, Alpha5 and Tumor2 cell lines. The percentage of the cells entering the specific phase of the cell cycle was determined by flow cytometric analysis of propidium iodide-stained cells.
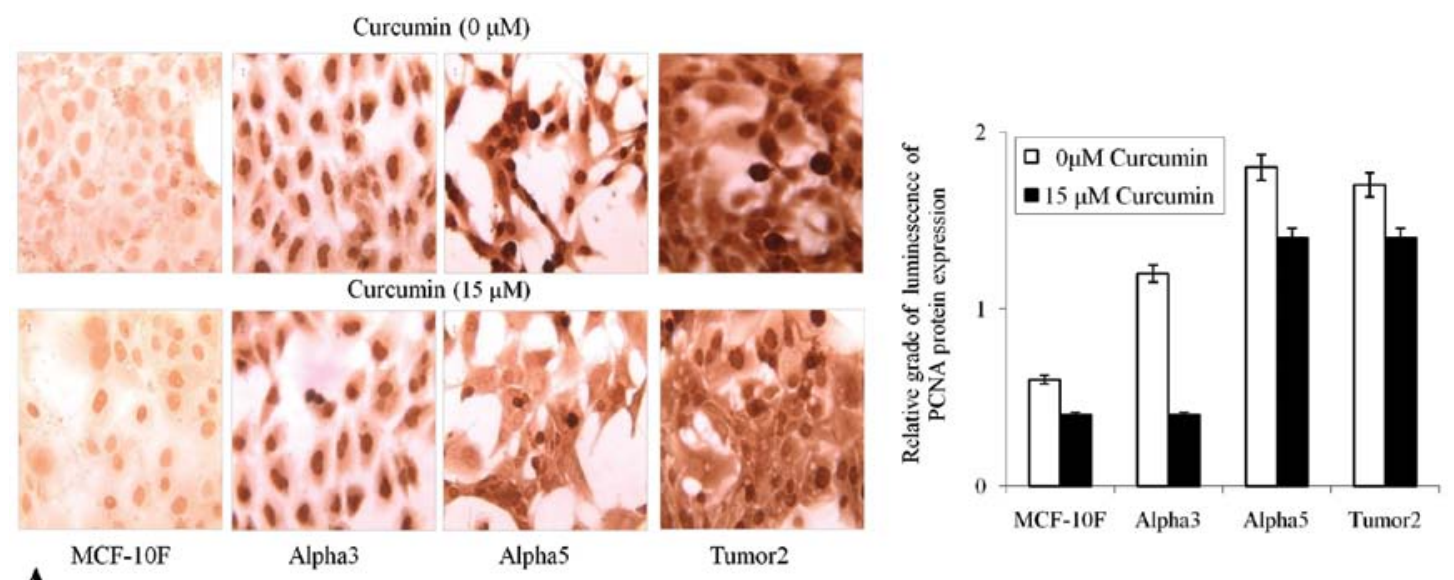

A

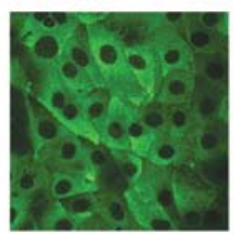

Curcumin $(0 \mu \mathrm{M})$
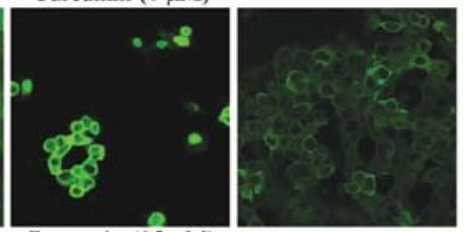

Curcumin $(15 \mu \mathrm{M})$
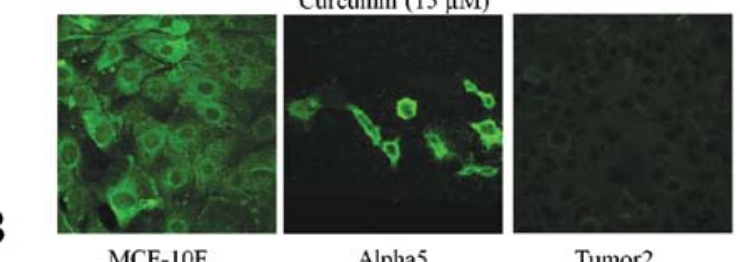

Alpha5

Tumor2

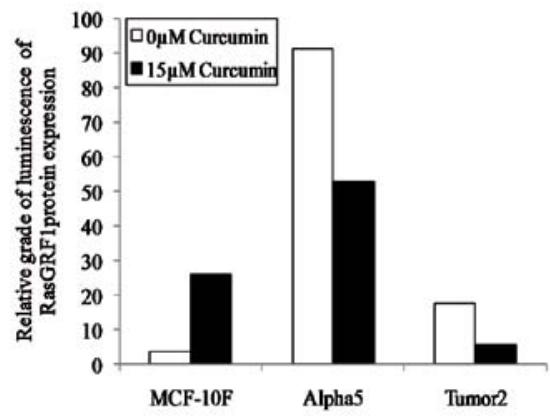

Figure 3. Effect of curcumin treatment $(0$ and $15 \mu \mathrm{M})$ on (A) PCNA protein expression by immunoperoxidase method in MCF-10F, Alpha3, Alpha5 and Tumor 2 cell lines and (B) on Ras-GRF1 protein expressions by immunofluorescence method in MCF-10F, Alpha5 and Tumor2 cell lines; the graph represents the relative grade of luminescence to assess the protein levels by confocal microscope studies coupled with a computer Adobe Photoshop Program. 

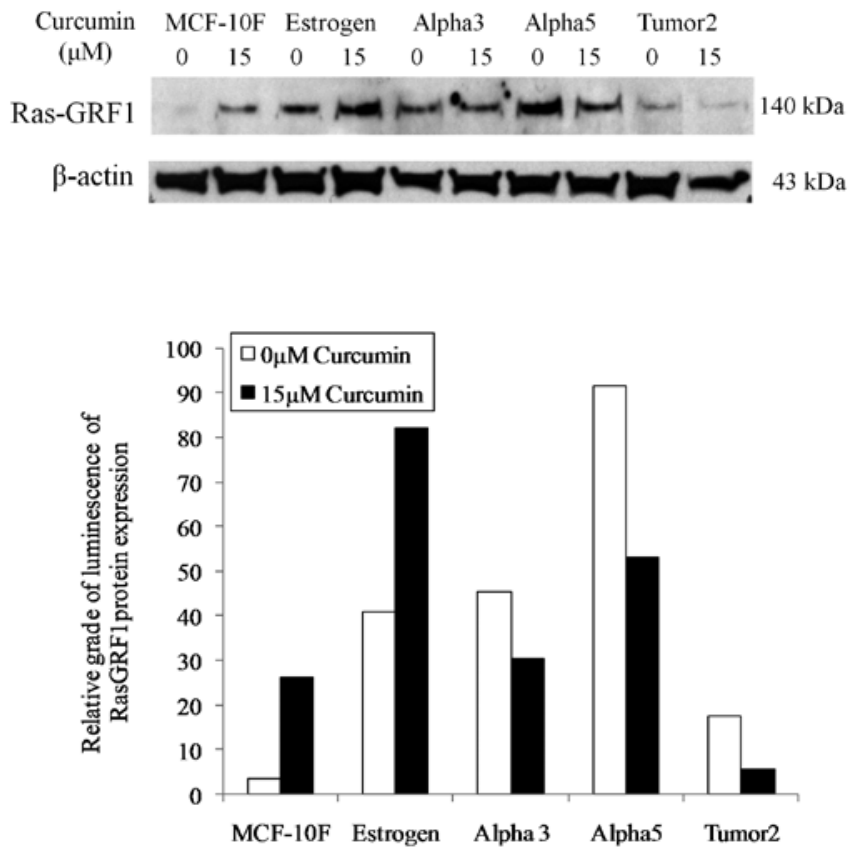

Figure 4. Effect of curcumin treatment $(0$ and $15 \mu \mathrm{M})$ on Ras-GRF1 protein expression determined by Western blot analyses in MCF-10F, Estrogen, Alpha3, Alpha5 and Tumor 2 cell lines, $\beta$-actin was used as control for loading. Graph represents the relative grade of luminescence to assess the protein level by Western blotting of the cell lines.
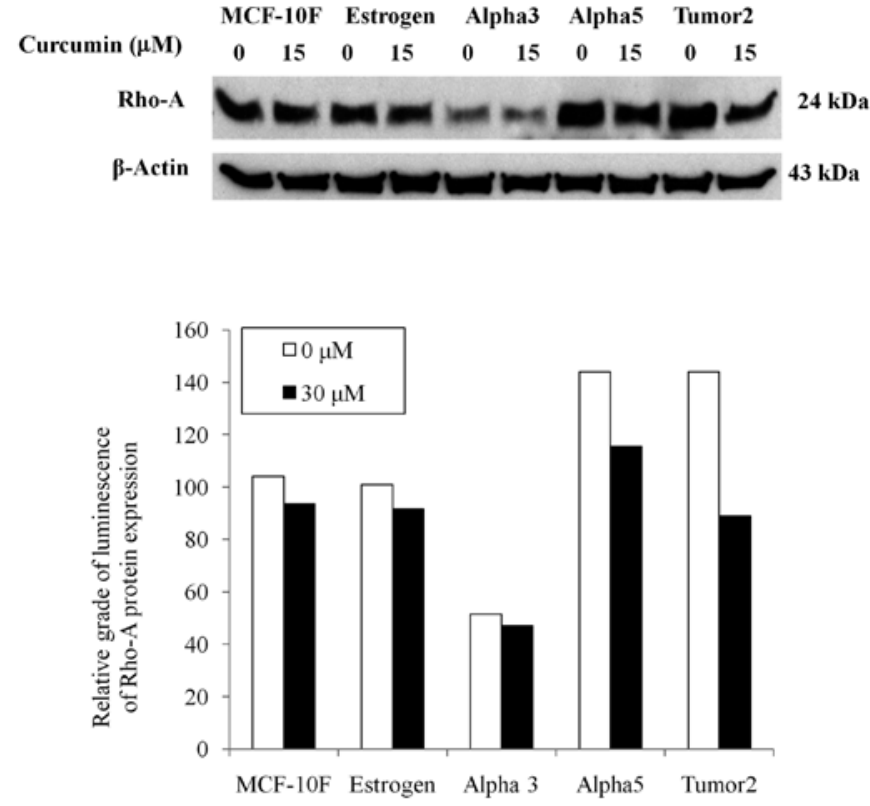

Figure 5. Effect of curcumin treatment $(0$ and $15 \mu \mathrm{M})$ on Rho-A protein expressions determined by Western blot analyses of MCF-10F, Estrogen, Alpha3, Alpha 5 and Tumor 2 cell lines. $\beta$-actin was used as control for loading. The graph represents the relative grade of luminescence to assess the protein level of the cell lines.

Effect of curcumin on DNA damage signaling: $\gamma$-H2AX determination. DSBs are generated during apoptosis when chromosomal DNA is cleaved into oligonucleosomal pieces and phosphorylated $\mathrm{H} 2 \mathrm{AX}(\gamma-\mathrm{H} 2 \mathrm{AX})$, forms discrete foci at the sites of DSBs, facilitating the remodeling complexes to the sites of DNA damage, and influences both the efficiency and fidelity of DSB repair. Differential expression levels of $\gamma-\mathrm{H} 2 \mathrm{AX}$ were observed after curcumin treatment (Fig. 6B). It was found in the whole cell lysate, that the $\gamma-\mathrm{H} 2 \mathrm{AX}$ protein expression detected in the MCF-10F, Alpha5 and Tumor2 was diminished upon curcumin treatment. There was no expression of phospho $\gamma-\mathrm{H} 2 \mathrm{AX}$ in the Alpha3 cell line with or without curcumin. However, there was an increase by curcumin in the Estrogen cell line. These results suggest that $\gamma-\mathrm{H} 2 \mathrm{AX}$ foci are stimulated in malignant and transformed Alpha5 and Tumor2 cell lines. On the other hand, the $\gamma-\mathrm{H} 2 \mathrm{AX}$ appear activated by curcumin treatment only in the Estrogen cell line, which possess a normal phenotype.

\section{Discussion}

Although accumulating evidence suggests that curcumin has a diverse range of molecular targets (5-8), effects of curcumin in normal and malignant cells are still largely unclear. To understand the effect of curcumin on breast carcinogenesis, we used an in vitro breast cancer model system in this study. The present study indicates that curcumin had a significant inhibitory effect on cell growth and colony formation in breast carcinogenesis and is able to activate DNA damage signaling.

Cell cycle analysis of these cell lines showed that $\mathrm{S}$ and $\mathrm{G}_{2} / \mathrm{M}$ phases were altered by curcumin by reducing the proportion of cells in $\mathrm{G}_{0} / \mathrm{G}_{1}$ phase and increasing the number of $\mathrm{G}_{2} / \mathrm{M}$ phase cells indicating that curcumin imposed a stronger $\mathrm{G}_{2} / \mathrm{M}$ checkpoint as compared to untreated cells but less in Tumor2. The effect was more pronounced in Alpha3 and Alpha5 than in Tumor 2 cells. That curcumin seems to inhibit cell proliferation, induce apoptosis, and promote accumulation of cells in the $\mathrm{G}_{2} / \mathrm{M}$ phase of the cell cycle has been demonstrated by several authors (14-18). Although cell cycle modulators are designed to target cancer cells, some of these can also be applied for a different purpose, as to protect normal cells against the lethality of chemotherapy (14). In some cell types like thymocytes, curcumin induced apoptosis-like changes whereas in many other normal and primary cells curcumin either stimulates or inhibits proliferation. Inhibition of both proliferation and apoptosis of T lymphocytes by curcumin led authors to conclude that the inhibition of cell proliferation by curcumin was not always associated with programmed cell death (14). Interestingly, curcumin has been found to inhibit proliferation of normal, non-selectively, as well as malignant cells, although its apoptogenic effect is more profound in malignant cells since it selectively induced apoptosis in deregulated cyclin D1-expressed cells at $\mathrm{G}_{2}$ phase of cell cycle in a p53-dependent manner $(10,25)$.

Ras proteins must first release bound GDP mediated by GRF to reach their active GTP bound state. Curcumin increased GRF1 protein expression of MCF-10F and E cell line with or without curcumin preventing the binding. The cell lines Alpha3, Alpha5 and Tumor2 had increased protein expression. However, curcumin decreased such expression increasing the binding.Results also showed that Rho-A protein expression decreased in the malignant cell lines Alpha3, Alpha5 and Tumor2 with $15 \mu \mathrm{M}$ curcumin but not in MCF-10F and Estrogen.

Previously, our laboratory demonstrated $(24,30-32)$ that the parental MCF-10F cell line exposed to double doses of 


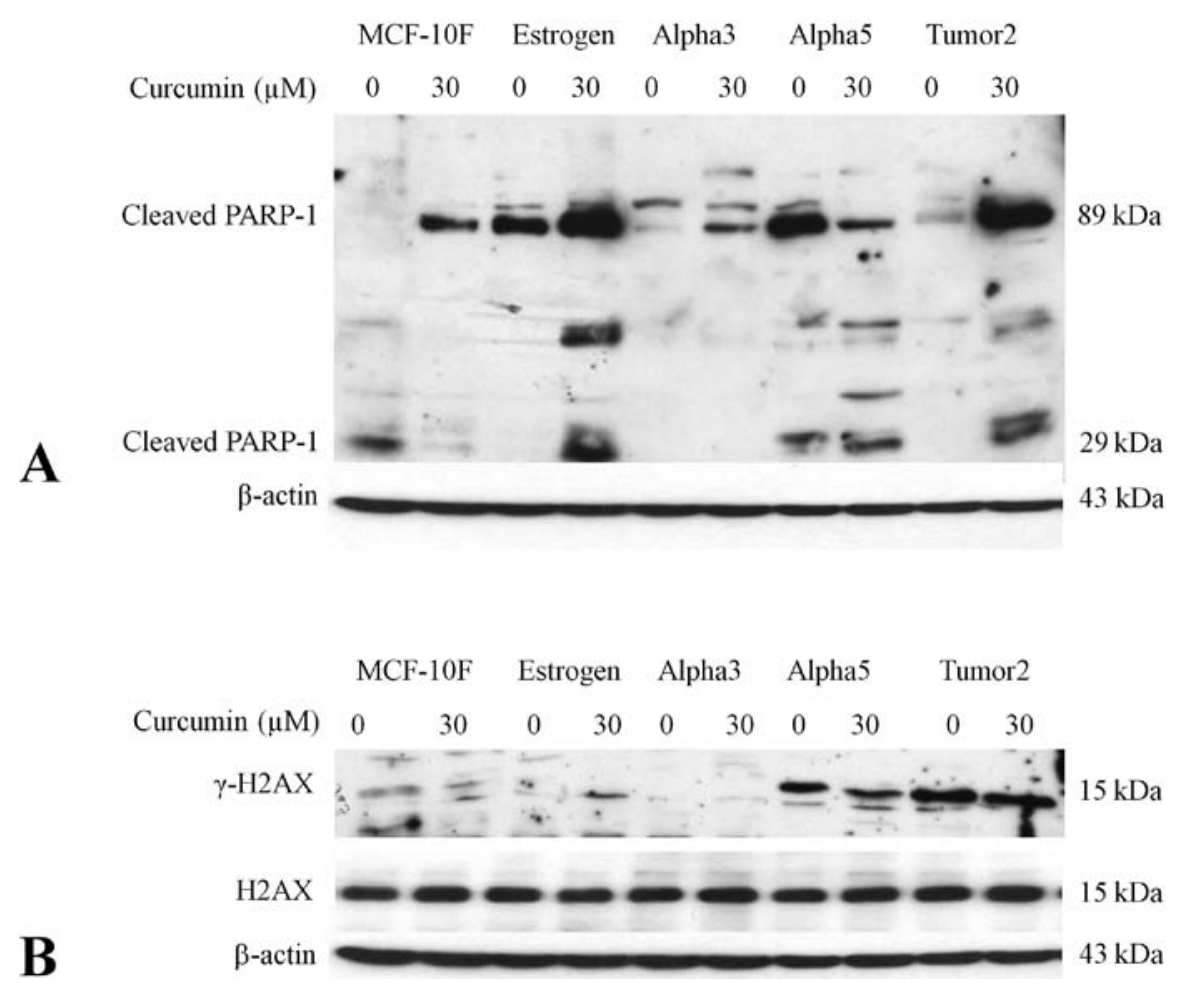

Figure 6. Effect of curcumin treatment ( 0 and $30 \mu \mathrm{M})$ on (A) cleaved PARP1 and (B) phospho H2AX and H2AX protein expressions in the cell lines: MCF-10F, Estrogen, Alpha3, Alpha5 and Tumor2 cell lines by Western blot analyses. $\beta$-actin was used as control for loading.

alpha-particle radiation and treated with estrogen showed a more complex pattern of allelic imbalance compared to cell lines treated with a single dose of radiation without estrogen. Exposure of cell lines to double doses of radiation without estrogen and analyzed at different passages also showed a progressive change. Allelic alterations induced by irradiation with either a single or double dose of alpha particles in the presence or absence of estrogen were expressed either in the form of loss of heterozygosity/microsatellite instability or by some phenotypic changes, such as anchorage independence or invasive capabilities. Consequently, the doses of radiation of the cell lines after irradiation directly influenced these alterations and this genetic effect was more deleterious when given in combination with estrogen. The $\mathrm{c}$-Ha-ras oncogene, mapped to $11 \mathrm{p} 15.5$, acquires transforming capacity either by single point mutation (s) in codon 12 or 61 , resulting in the expression of an aberrant gene product, or by over-expression of the normal c-Ha-ras p21 protein. Studies in rats have implicated c-Ha-ras mutations in the etiology of breast adenocarcinomas $(25,27-29)$ It is known that estrogen is a key requirement for the normal development of the mammary gland. Although, some reports have shown estrogen to affect c-Ha-ras expression (26).

The present results showed that PARP-1 was cleaved upon curcumin treatment in malignant and tumorigenic cells. Cleaved PARP-1 protein was increased in the presence of curcumin in the control MCF-10F and Estrogen cell lines, as well as in the malignant Alpha3 and the tumor cell line Tumor2. However, it was reduced in Alpha5 cell line indicating that PARP-1 was cleaved upon curcumin treatment in malignant and tumor cells. Curcumin (26) induced apoptosis in tumor cells by activating caspase- 8 , which leads to activation of caspase- 9 and -3 , and activation of PARP-1 and apoptosis of tumor cells. Pretreatment with curcumin enhanced the cleavage of PARP-1 in an ovarian cancer cell line after exposure with cisplatin indicating induction of apoptosis $(32,33)$.

The $\gamma$-H2AX protein expression was overexpressed in MCF-10F and diminished upon curcumin treatment. There was no expression of $\gamma-\mathrm{H} 2 \mathrm{AX}$ in the Estrogen cell line or Alpha3. However, there was an increase by curcumin effect in the expression in Alpha5 and Tumor 2 cell lines by curcumin. Thus, DNA double-strand breaks induced histone H2AX phosphorylation as reported by others (35). Therefore, it can be concluded that PARP-1 and H2AX confer cellular protection against radiation and estrogen-induced DNA damage when curcumin is present.

Targeting either PARP-1 or histone H2AX may provide an effective way of maximizing the therapeutic value of antioxidants for cancer prevention. It is important to point out that curcumin had an effect only on the malignant cell lines and not on the controls, indicating that it can be considered as an important substance for prevention of breast cancer. It can be concluded from these studies that curcumin had significant inhibitory effect on cell growth in breast carcinogenesis. Alteration of multiple protein expressions involved in key signaling pathways render this model an important tool for monitoring the effects of natural dietary compounds in breast carcinogenesis.

\section{Acknowledgements}

This study was supported by grant FONDECYT \#1080482 (G.M.C.). 


\section{References}

1. Kunnumakkara AB, Anand P and Aggarwal BB: Curcumin inhibits proliferation, invasion, angiogenesis and metastasis of different cancers through interaction with multiple cell signaling proteins. Cancer Lett 269: 199-225, 2008.

2. Limtrakul P, Lipigorngoson S, Namwong O, et al: Inhibitory effect of dietary curcumin on tumorigenesis in mice. J Biochem 27 (Supppl.): 26-34, 1997.

3. Sharma RA, Euden SA, Platton SL, et al: Phase I clinical trial of oral curcumin biomarkers of systemic activity and compliance. Clin Cancer Res 10: 6847-6854, 2004

4. Cruz-Correa M, Shoskes DA, Sanchez P, et al: Combination treatment with curcumin and quercetin of adenomas in familial adenomatous polyposis. Clin Gastroenterol Hepatol 4: 1035-1038, 2006.

5. Aggarwal BB, Surth YH and Shishodia S: The molecular targets and therapeutics of curcumin in health and disease. Advances in Experimental Biology. Springer Publ, Vol. 995: 2007.

6. Agarwal A, Mahfouz RZ, Sharma RK, et al: Potential biological role of poly (ADP-ribose) polymerase (PARP) in male gametes. Reprod Biol Endocrinol 7: 143, 2009.

7. Aggarwal BB, Bhatt ID, Ichikawa H, et al: Curcumin-Biological and Medicinal Properties. The CRC Press, Boca Raton, FL, pp297-368, 2006.

8. Aggarwal BB, Kumar A and Bharti AC: Anticancer potential of curcumin: preclinical and clinical studies. Anticancer Res 23: 363-398, 2003.

9. Aggarwal BB, Shishodia S, Takada Y, et al: Curcumin suppresses the paclitaxel-induced nuclear factor-kappaB pathway in breast cancer cells and inhibits lung metastasis of human breast cancer in nude mice. Clin Cancer Res 11: 7490-7498, 2005.

10. Ruby AJ, Kuttan G, Babu KD, Rajasekharan KN and Kuttan R: Anti-tumour and antioxidant activity of natural curcuminoids. Cancer Lett 94: 79-83, 1995.

11. Kuttan R, Bhanumathy P, Nirmala K and George MC: Potential anticancer activity of turmeric (Curcuma longa). Cancer Lett 29: 197-202, 1985

12. Conney AH, Lysz T, Ferraro T, et al: Inhibitory effect of curcumin and some related dietary compounds on tumor promotion and arachidonic acid metabolism in mouse skin. Adv Enzyme Regul 31: 385-396, 1991.

13. Bachmeier B, Nerlich AG, Iancu CM, et al: The chemopreventive polyphenol Curcumin prevents hematogenous breast cancer metastases in immunodeficient mice. Cell Physiol Biochem 19: 137-152, 2007.

14. Ranjan D, Chen C, Johnston TD, et al: Curcumin inhibits mitogen stimulated lymphocyte proliferation, NFkappaB activation, and IL-2 signaling, J Surg Res 121: 171-177, 2004.

15. Choudhuri T, Pal S, Das T and Sa G: Curcumin selectively induces apoptosis in deregulated cyclin D1-expressed cells at G2 phase of cell cycle in a p53-dependent manner. J Biol Chem 280: 20059-20068, 2005

16. Ramachandran C, Rodriguez S, Ramachandran R, et al: Expression profiles of apoptotic genes induced by curcumin in human breast cancer and mammary epithelial cell lines. Anticancer Res 25 3293-3302, 2005.

17. Hartojo W, Silvers AL, Thomas DG, et al: Curcumin promotes apoptosis, increases chemosensitivity, and inhibits nuclear factor kappaB in esophageal adenocarcinoma. Transl Oncol 3: 99-108, 2010.

18. Wang Z, Zhang Y, Banerjee S, Li Y and Sarkar FH: Notch-1 down-regulation by curcumin is associated with the inhibition of cell growth and the induction of apoptosis in pancreatic cancer cells. Cancer 106: 2503-2513, 2006.

19. Jiang Z, Jin S, Yalowich JC, Brown KD and Rajasekaran B: The mismatch repair system modulates curcumin sensitivity through induction of DNA strand breaks and activation of G2-M checkpoint. Mol Cancer Ther 9: 558-568, 2010.
20. Aznar S and Lacal JC: Rho signals to cell growth and apoptosis Cancer Lett 165: 1-10, 2001.

21. Schmitz AA, Govek EE, Böttner B and van Aelst L: Rho GTPases: signaling, migration, and invasion. Exp Cell Res 261: 1-12, 2000.

22. Shin EY, Kim SY and Kim EG: c-Jun N-terminal kinase is involved in motility of endothelial cell. Exp Mol Med 33: 276-283, 2001.

23. Limtrakul P, Anuchapreeda S, Lipigorngoson S and Dunn FW: Inhibition of carcinogen-induced c-Ha-ras and c-fos proto-oncogenes expression by dietary curcumin. BMC Cancer 1: 1, 2001.

24. Roy D, Calaf GM and Hei TK: Allelic imbalance at 11p15.5-15.4 correlated with $\mathrm{C}$-Ha-Ras mutation during radiation-induced neoplastic transformation of human breast epithelial cells. Int J Cancer 103: 730-737, 2003

25. Bos JL: The ras gene family and human carcinogenesis. Mutat Res 195: 255-271, 1988 .

26. Thor A, Qhuchi N and Hand PN: Ras gene alterations and enhanced levels of ras p21 expression in a spectrum of benign and malignant human mammary tissues. Lab Invest 55: 603-615, 1986.

27. Theillet C, Liderau R, Escot C, et al: Loss of a c-H-ras-1 allele and aggressive human primary breast carcinomas. Cancer Res 46: 4776-4781, 1986

28. Kiaris H and Spandidos DA: Mutations of ras genes in human tumours. Int J Oncol 7: 413-429, 1995

29. Dickson RB, Kasid A, Huff KK, et al: Activation of growth factor secretion in tumorigenic states of breast cancer induced by 17 beta-estradiol or v-Ha-ras oncogene. Proc Natl Acad Sci USA 84: 837-841, 1987.

30. Roy D, Calaf GM and Hei TK: Allelic imbalance at 11q23-q24 chromosome associated with estrogen and radiation-induced breast cancer progression. Int J Oncol 28: 667-674, 2006.

31. Roy D, Calaf GM and Hei TK: Profiling of differentially expressed genes induced by high linear energy transfer radiation in breast epithelial cells. Mol Carcinog 31: 192-203, 2001.

32. Rouleau M, Patel A, Hendzel MJ, et al: PARP inhibition: PARP1 and beyond. Nat Rev Cancer 10: 293-301, 2010.

33. Kirkland JB: Poly ADP-ribose polymerase-1 and health. Exp Biol Med 235: 561-568, 2010

34. Kinsella TJ: Coordination of DNA mismatch repair and base excision repair processing of chemotherapy and radiation damage for targeting resistant cancers. Clin Cancer Res 15: 1853-1859, 2009.

35. Rogakou EP, Pilch DR, Orr AH, et al: DNA double-stranded breaks induce histone H2AX phosphorylation on serine 139. J Biol Chem 273: 5858-5868, 1998.

36. Fernandez-Capetillo O,Lee A, Nussenzweig M and Nussenzweig A: H2AX: the histone guardian of the genome. DNA Repair (Amst) 3: 959-967, 2004.

37. Meador JA, Zhao M, Su Y, et al: Histone H2AX is a critical factor for cellular protection against DNA alkylating agents. Oncogene 27: 5662-5671, 2008

38. Calaf GM and Hei TK: Establishment of a radiation- and estrogen-induced breast cancer model. Carcinogenesis 21: 769-776, 2000

39. Calaf $\mathrm{G}$ and Hei TK: Oncoprotein expression in human breast epithelial cells transformed by high- LET radiation. Int J Radiat Biol 77: 31-40, 2001.

40. Calaf GM, Roy D and Hei TK: Immunochemical analysis of protein expression in breast epithelial cells transformed by estrogens and high linear energy transfer (LET) radiation. Histochem Cell Biol 124: 261-274, 2005.

41. Soule HD, Maloney TM, Wolman SR, et al: Isolation and characterization of a spontaneously immortalized human breast epithelial cell line, MCF-10. Cancer Res 50: 6075-6086, 1990. 